\title{
What has Vela Uniform Accomplished?
}

IN December, 1968, Nature drew attention to the report of a group of seismologists on the capabilities of the present day global seismic network to discriminate between earthquakes and nuclear tests (SIPRI: seismic methods for monitoring underground explosions, Stockholm, 1968). Although it would be folly to think that the next logical step in nuclear arms control-a comprehensive test ban-is going to be determined by seismological capability, an adequate verification system has always been a requisite for the Western Powers and, ono suspects, an excuse for doing nothing "until the system is competent". As the definition of competence is not spelt out, politicians are able to redefine it at will and, since there will always be a puddle of detected but unidentified events, it is for politicians to decide whether they think this puddle could jeopardize a nation's security or whether it is possible to turn a blind eye to small events. In any case, a series of small tests is bound to attract attention and push to a high value the probability that, as a whole, the series can be identified as man-made.

Response to the SIPRI report so far has been encouraging. It has been welcomed as authoritative and fairly optimistic. To be sure, it is certainly possible to pick holes in the report-in places it was internally inconsistent and sometimes plain wrong, but the reason for this was probably that not all the data which could be useful were declassified. A case in point is the yields of Soviet test explosions; another (if the assertion of Dr D. Davies in November's Science Journal is to be believed) is the information from a classified American network of seismic detectors.

Predictably, the political reaction told more about political postures than seismology. The Soviet Union has never doubted its ability to identify underground explosions. The non-committed nations, already under pressure to sign away their nuclear birthright, seized on the report as a crowbar to prise some compensation from the Super-Powers. The United Kingdom has rather lamely raised the inspection issue-complete anathema to the Super-Powers. Indeed, Mr F. Mulley's speech to the Eighteen Nation Committee on Disarmament in Geneva on July 16, 1968, gives the impression that he was at that stage ignorant of the existence of the SIPRI group, whose summary was published on June 27, 1968.

United States reaction is presumably enshrined in Mr William Foster's statement to United Nations Committee I on disarmament on December 5, 1968, when he warned against drawing unwarranted conclusions from the report and observed that careful reading of the summary report left no doubt that participants at the SIPRI meetings were agreed that sizable explosions, in the range of many tens of kilotons, could not be differentiated from earthquakes. This is an over-cautious reading of the report. It also implies that the United States is less than satisfied with Project Vela Uniform, which was initiated on the recommendations of the Berkner Panel in 1959. Its terms of reference were to carry out a comprehensive research programme in seismology and to develop equipment for monitoring underground explosions. In the past eight years, more than $\$ 200$ million has been spent in basic seismic research, development of a superb worldwide network of stations, initiation of arrays and the provision of data to all comers. From the seismologist's point of view, the project has been manna from heaven, giving an enormous boost to a previously under-instrumented under-manned subject. But if the official line is that the threshold is still too high to negotiate, it would seem that the ultimate purpose of Vela Uniform has not been achieved.

A careful study of Mr Foster's speech, however, may suggest a more optimistic view. He speaks of explosions in the range of many tens of kilotons as being unidentifiable. To many people this presumably will mean that explosions of 50 kilotons are and always will be testable with a good chance of secrecy. But the summary of the SIPRI meeting projected detection capabilities into the future and concluded that an improved seismographic network based on that initiated by Project Vela Uniform would be able to discriminate down to the present generally accepted threshold about 10 kilotons in granite. It also indicated that research in the $2-10 \mathrm{kT}$ (in granite) range was possible and certainly should not be rejected out of hand. Even allowing for the fact that detonations in less compacted material will have a smaller seismic effect $(30 \mathrm{kT}$ in some sedimentary rock may look like $10 \mathrm{k} T$ in granite), the future is only as bleak as the politicians want to make it. No violator in his right mind would dream of going within a factor of two of the threshold-geology is delightfully unpredictable from this point of view. When the improved network which the United States has proposed comes into operation, violators will have to watch their steps above about $15 \mathrm{kT}$ in practically any rock.

Project Vela Uniform now begins to look more worthwhile because these figures are edging much nearer to those that politicians know they will eventually have to concede as acceptable. The World. Wide Standard Seismograph Network (WWSSN) with its improvements looks like being an even more powerful tool in a year or two, and Vela Uniform will take full credit for nursing it along. This is why it is strange that when the network promises to be so important, there were indications last year of a loss of interest by the Advanced Research Project Agency. Support is now in the hands of the Environmental Science Services 
Administration which, through the Coast and Geodetic Survey, has had difficulties in sustaining it at the high level seismologists have come to expect. Could it be that this loss of interest is a sign that the WWSSN is now obsolete as far as nuclear tests are concerned? If so, it follows that the classified network must be doing at least as well. Perhaps it can already discriminate down to $10 \mathrm{kT}$ in granite? Or even better? The United States can, of course, hold on to this information, which may be the answer to all verification problems, as long as it is politically expedient to do so. But if the Arms Control and Disarmament Agency can tell the world that it strongly supports an adequately verified test ban when the Nuclear Safeguards Subcommittee is promising more testing programmes, nobody can really know where the United States stands. It is no wonder that many seismologists who have given Vela Uniform many years of hard work are now studying the inner core, developing moonquake seismometers or studying the characteristics of earthquakes on mid-ocean ridges.

\section{STUDENT TROUBLES \\ Sit-in af Chicago}

\section{from a Special Correspondent}

Chicago, February 3

A SMALL number of students at the University of Chicago has been looking for an opportunity to confront the administration, particularly since the new president, Edward Levi, came into office. In September there was a walk-out and a sit-in over fair treatment for cafeteria workers which came to nothing. These were followed by vigorous protests about student housing, which became linked with urban renewal and the university's role in the development of neighbouring residential areas. Housing was an issue because Chicago, in common with many other universities, had anticipated a larger toll from the draft than was in fact exacted. The administration did its best in an impossible situation, with wholesale bookings of hotel rooms.

The present sit-in appears to have been triggered by the university's notice to Dr Marlene Dixon, an assistant professor with a joint appointment in the Department of Sociology and on the Committee of Human Development, that hor three-year contract would not be rencwed on September 30, 1969. This notice was given on December 15. Similar notices were of course given to other assistant professors. Assistant; professors are normally employed on a three-ycar contract which may be renewed for a further three years, after which the question of promotion to associate professor with tenure arises. Renewal is by no means automatic, and reasons for not renewing a contract are naturally not disclosed. Nonetheless, on January 9, an ad hoc group of students called the Committee of 85 demanded that Dr Dixon be reappointed and that students be given an equal vote on decisions to hire or fire faculty.

The dean of the Division of Social Sciences, D. Gale Johnson, responded on January 13 by calling an open meeting for the 17th to discuss problems of appointments. He made it clear that individual faculty appointments could not be discussed, but he asked that a faculty committee be set up to review his decision. not to reappoint Dr Dixon. This committee is now sitting and will report early next week. On the 23rd the Committee of 85 turned its demands into an ultimatum, saying that militant action would be taken if they were not met by January 29. Occupation of the administration building started on the 30th.

It was plain from the beginning that the university would avoid physical confrontation at all costs and would resort only in dire extremity to an injunction which might have to be enforced by city police. However, the situation is beginning to take on more of the elements of fantasy with, for example, threats to take over more buildings and demands that 51 per cent of the faculty be women and that one-third of the student intake should be negro or "third world"'- that is, from Puerto Rican or other minority groups.

The vast majority of the 8,600 students and the 1,100 faculty is united in opposition to the sit-in, although many feel that it has provided a needed. stimulus for open discussion of issues that were previously ignored. The University of Chicago, however, has a very liberal administration which-to this observer at any rate-seems to have been making every reasonable effort to listen to student opinion and to play a constructive part in the city, particularly in its attempts to advance the education of members of minority groups. It has initiated programmes to find talented children at an early age and to prepare them for a university education. It has eschewed the more histrionic but inevitably hopeless gesture of admitting numbers of students who cannot cope with the course material offered. This has been tried at other universities but has always been a dismal failure. It seems that the sit-in, which is led by a small number of students and which has never attracted more than 250 at once, is symptomatic of the general malaise particularly evident in universities with large schools devoted to the social sciences. What is certain is that no university would agree to sharing between the faculty and the students responsibility for recruiting and dismissing staff. At Chicago, only tenured faculty with a long term interest in the university can vote on such issues, although the opinions of junior faculty and of students are canvassed.

\section{SATELLITES}

\section{Another Look af the lonosphere}

ISIS-A, launched from NASA's Wcstern Test Range on January 30 , is one of the most heavily instrumented ionosphere probes ever launched. It is also Canada's third satellite, following the two Alouettes into orbit. The Defonce Research Board will be hoping that it will be just as successful, although it is a much more complicated package than either of its predecessors. It carries eleven experiments, from the Defence Research Telecommunications Establishment at Ottawa, NASA, the National Research Council of Canada, the US Air Force Cambridge Laboratories, the University of Western Ontario and the US Southwest Center for Adranced Studies. The satellite has gone into an elliptical orbit with an inclination of $88.5^{\circ}$ and a period of just over two hours; at apogee, the satellite is 3,522 kilometres from the Earth, and at 